Effects of turbidity on prey choice of three-spined stickleback Gasterosteus aculeatus

\title{
Sohel, Shakwat
}

2017-02-27

Sohel , S , Mattila , J \& Lindström , K 2017 , ' Effects of turbidity on prey choice of three-spined stickleback Gasterosteus aculeatus ' , Marine Ecology. Progress Series, vol. 566 , pp. 159-167 . https://doi.org/10.3354/meps 12014

http://hdl.handle.net/10138/339504

https://doi.org/10.3354/meps 12014

publishedVersion

Downloaded from Helda, University of Helsinki institutional repository.

This is an electronic reprint of the original article.

This reprint may differ from the original in pagination and typographic detail.

Please cite the original version. 


\title{
Effects of turbidity on prey choice of three-spined stickleback Gasterosteus aculeatus
}

\author{
Shakwat Sohel ${ }^{1}$, Johanna Mattila ${ }^{1,2}$, Kai Lindström ${ }^{1, *}$ \\ ${ }^{1}$ Environmental and Marine Biology, Åbo Akademi University, 20520 Turku, Finland \\ ${ }^{2}$ Present address: Department of Aquatic Resources, Swedish University of Agricultural Sciences, Skolgatan 1, \\ 74242 Öregrund, Sweden
}

\begin{abstract}
Fishes largely depend on visual cues to collect information from their surroundings. In many aquatic habitats, algal turbidity has become an imminent environmental concern. Algal turbidity reduces visibility and may therefore interact with prey preference by altering prey detection and foraging behaviour of predators. We investigated the effects of algal turbidity on prey choice decisions of 3-spined sticklebacks Gasterosteus aculeatus in 2 experiments manipulating turbidity levels (clear $<1,5,10,15$ and 20 nephelometric turbidity units [NTU] in Expt 1 ; clear $<1$ and 15 NTU in Expt 2) and the proportion of prey items-large (1.8-2.0 mm) and small $(0.8-1.0 \mathrm{~mm})$ water fleas Daphnia magna. We found an overall negative effect of turbidity on prey consumption by stickleback. Prey selectivity was most pronounced in clear and 5 NTU water, whereas at higher turbidity levels, selectivity decreased. As the ratio of large to small prey increased, the fish became less selective. In addition, we found an interaction effect between turbidity and fish size on the total number of prey consumed. These results indicate that algal turbidity affects the prey choice decisions of sticklebacks, probably because turbidity limits their visual field. Consequently, as fish feed more randomly in turbid water, the structuring effect of fish predators on zooplankton communities will be reduced in turbid environments.
\end{abstract}

KEY WORDS: Algal turbidity $\cdot$ Diet choice $\cdot$ Optimal foraging $\cdot$ Zooplankton $\cdot$ Predator-prey

\section{INTRODUCTION}

To optimize foraging success, predators need to decide which of alternative prey items to feed on (Stephens \& Krebs 1986). This decision is among other things based on prey profitability and encounter rates (Dill 1983), and the optimal diet model predicts when a predator should switch from random feeding to being selective (Werner \& Hall 1974, Stephens \& Krebs 1986). However, optimal foraging requires that an animal has complete information on the profitability of alternative prey and that it is able to recognize the alternatives (Zhang \& Hui 2014). In most situations, vision provides fast and accurate information about the surroundings and resources and prey identification. Many fish species rely on vision as their main sense when searching for food (Guthrie \& Muntz 1993). However, the underwater environment often compromises visibility and hence information quality. Water turbidity further decreases visibility by reducing light intensity (UtnePalm 2002). Turbidity can be caused by mass occurrences of planktonic algae, while sediment turbidity can result from decaying organic material or dissolved sediments of aquatic or terrestrial origin.

Many aquatic ecosystems experience increased eutrophication (Selman et al. 2008) with ensuing increases in turbidity that affect water clarity. For example, in the Baltic Sea, turbidity levels along the coasts have increased during the last few decades, causing a significant decrease in visibility (measured as Secchi depth; Sanden \& Håkansson 1996). It is 
widely believed that turbidity can alter predator-prey interactions (Reguera \& Gomendio 1999, Sweka \& Hartman 2001) and significantly change fish community structure (Blaber \& Blaber 1980, Bonner \& Wilde 2002). An increase in turbidity can have a general negative effect on fish stocks in coastal and estuarine aquatic systems (Aksnes 2007). A potential reason could be that visually foraging predatory fishes suffer reduced foraging efficiency as turbidity increases (Sweka \& Hartman 2001, Utne-Palm 2002, Sweka \& Hartman 2003, Shoup \& Drew Lane 2015). However, some studies have shown that foraging success is unaffected by turbidity (Rowe et al. 2003, Granqvist \& Mattila 2004) or may even moderately increase in some species (Rowe \& Dean 1998, De Robertis et al. 2003). In addition, the type of prey and turbidity can affect how predators perform (Jönsson et al. 2012, Jönsson et al. 2013). Turbidity could also lower the risk of predation (Gregory \& Northcote 1993, De Robertis et al. 2003), thus allowing foragers to focus more on feeding. Thus, it seems that under some conditions, elevated turbidity levels could also be beneficial. Whether algal or sediment turbidity have different effects on fish foraging is debatable. Recent studies (e.g. the ones cited above) show variable results, but in general, both types of turbidity seem to have a negative effect on foraging success.

Turbidity could have a negative effect on the ability of foragers to make optimal prey choices, although this has been relatively unexplored so far. If turbidity does hamper the ability of predators to exert active prey choice, this could have substantial consequences for the impact of predation on the community structure of prey. Prey selection is often based on the profitability of prey, where the greatest energetic profitability is defined as the prey that gives the maximum energy gain per unit handling time (Stephens \& Krebs 1986). In a situation of encountering prey sequentially, a forager's choice between more and less profitable prey is predicted to depend on the encounter rate with the more profitable prey (Werner \& Hall 1974). Assessing the profitability of 2 different prey types is presumably difficult and takes up a large part of the time budget of a feeding fish (Ohguchi 1981), and may become even more difficult in deteriorating environments.

The 3-spined stickleback Gasterosteus aculeatus is a good model species with which to study effects of turbidity on foraging behaviour because sticklebacks are visual feeders (Gill \& Hart 1994). Stickleback populations are geographically widespread in marine and freshwater environments (Bell \& Foster 1994), and many parts of these areas are affected by periodic algal turbidity (Sanden \& Håkansson 1996, Valiela et al. 1997). Sticklebacks frequently feed on small crustaceans and zooplankton, such as Daphnia spp. (Wootton 1976). In this study, we used Daphnia magna as prey because these are easy to collect in large quantities, easy to sort into different size classes and are relatively slow at escaping once they have been detected by feeding sticklebacks. Like many other zooplankton, they are inconspicuous by being small and relatively transparent (Johnsen \& Widder 1998). Evidence from natural populations and laboratory experiments shows that numerous internal and external factors (e.g. habitat structure, parasitic load, predator presence, sexual state, prey size, prey abundance, stomach fullness and memory) influence prey selection by sticklebacks (Hart \& Gill 1994). In nature, stickleback populations increasingly face turbid conditions. A number of recent studies have addressed the effects of turbidity on prey detection and foraging success of sticklebacks and other fishes (Utne 1997, Utne-Palm 1999, Vogel \& Beauchamp 1999, Quesenberry et al. 2007, Salonen et al. 2009, Carter et al. 2010, Salonen \& Engström-Öst 2010). Studies have also examined prey selection in relation to turbidity, but most of these studies have involved prey of different species with different biology that may require very different behaviour to catch and devour by the predator (Stuart-Smith et al. 2007, Shoup \& Wahl 2009, Helenius et al. 2013, Figueiredo et al. 2015). Gardner (1981a) examined prey selectivity in bluegill sunfish Lepomis macrochirus feeding on equal availability of 2 different size classes of Daphnia. By providing sticklebacks a range of different proportions of small and large prey of a single species, we highlight the importance of prey size (energy content) for foraging decisions, while minimising the effects of other factors. This allows us to focus on how turbidity affects the choice of low and high-energy prey items.

Here, we tested experimentally how different turbidity levels (created by planktonic algae), prey densities and prey size distribution (number of large to small prey, hereafter called 'prey size ratio') affect prey selectivity in the 3 -spined stickleback. We used water fleas $D$. magna of 2 different size classes. Prey profitability in our study is therefore only affected by size and not confounded by many other factors, such as behaviour and morphology that may affect the qualities of food objects as prey.

We hypothesised that the foraging success (prey consumption) of sticklebacks will decrease with increasing turbidity as turbidity limits the field of view. We further hypothesised that this limitation of 
the search area will limit the stickleback's ability to feed selectively, and instead the distribution of prey types in their diet will follow the availability of these prey in the environment (see also Gardner 1981b). This means that sticklebacks feeding in turbid water will no longer express prey selectivity but will feed randomly.

\section{MATERIALS AND METHODS}

We conducted 2 separate experiments following similar experimental procedures but with different experimental designs. The first experiment (Expt 1) was conducted at Husö Biological Station $\left(60^{\circ} 17^{\prime} \mathrm{N}\right.$, $\left.19^{\circ} 50^{\prime} \mathrm{E}\right)$ on the Åland Islands, the northern Baltic Sea, from May to July 2007. In this experiment, we tested total prey consumption and prey selectivity of sticklebacks using a wide range of turbidity levels. The aim was to test if increasing turbidity levels have an effect on total prey consumption and prey selectivity when the density of the more profitable (large) prey is increased. By increasing the density of the large prey, we simultaneously changed the ratio of profitable to less-profitable (small) prey and increased the total (large + small) density of prey. The second experiment (Expt 2) was conducted at

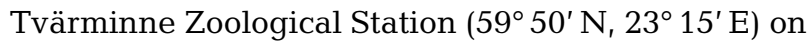
the south coast of Finland, from June to July 2009. Here, we explicitly tested foraging performance at 3 different ratios of small and large prey while keeping total density constant. We did this at 2 turbidity levels.

We caught 3-spined sticklebacks Gasterosteus aculeatus with a small beach seine close to the stations and took them to the laboratory within $1 \mathrm{~h}$ of the catch. In the laboratory, only non-breeding, adult females (length range 5.0 to $7.0 \mathrm{~cm}$; weight range 1.80 to $3.00 \mathrm{~g}$ ) were selected. The selected fishes were housed in several stock tanks (water temperature 12 to $18^{\circ} \mathrm{C}$; salinity 5.20 to $5.45 ; 75$ fish per tank of size $80 \times 40 \times 40 \mathrm{~cm}$ ) with continuous flow-through of seawater for 2 to $3 \mathrm{wk}$ to acclimatize them to laboratory conditions.

At Husö Biological Station, the stock tanks were placed inside a wet lab where the day-night regime was maintained manually at $16 \mathrm{~h}$ light: $8 \mathrm{~h}$ dark to mimic the natural photoperiod. At Tvärminne Zoological Station, the tanks were placed in an outdoor laboratory with transparent roof and walls, and the fish were acclimatised under natural light and temperature. During the acclimation period, fish were fed ad libitum with live Mysis spp., Daphnia spp. and frozen Chironomidae spp. larvae. The fish were fed once a day at 18:00 $\mathrm{h}$.

For the experiments, we collected water fleas Daphnia magna from nearby rock pools and sorted them into 2 size groups using a sieve. We defined these 2 group sizes as 'large' ( 1.8 to $2 \mathrm{~mm}$ ) and 'small' (0.8 to $1 \mathrm{~mm}$ ) (Milinski 1982, Ranta \& Lindström 1990). We chose Daphnia having similar colour (grey) and discarded any that were carrying ephippia in order to avoid using prey of varying conspicuousness.

Turbid water was generated by culturing the harmless green flagellate Brachiomonas submarina, which has been used in many studies. The initial strain of $B$. submarina was obtained from the culture collection at Tvärminne Zoological Station (strain TV15); for culturing, we followed the methodology described by Järvenpää \& Lindström (2004). The turbidity level (nephelometric turbidity unit [NTU]) was measured with a turbidity meter (Hach 2100P). We set the desired level of turbidity manually before the trial, and it remained at a satisfactory level (within \pm 1 NTU) during the trials.

Experimental trials were conducted during daytime between 11:00 and 16:00 h. In Expt 1 at Husö, the trials were conducted inside the wet lab, under fluorescent light. In Expt 2 at Tvärminne, the trials were conducted under ambient natural light conditions. In both cases, water temperature varied between 14 and $18^{\circ} \mathrm{C}$. The experimental tanks had a bottom area of $35 \mathrm{~cm} \times 40 \mathrm{~cm}$, and the water level was maintained at $20 \mathrm{~cm}$. A black curtain surrounded the entire experimental areas to minimise outside disturbance. The turbidity levels ( $<1$ to 20 NTU) during the experiments were selected according to previous studies (Shaw et al. 2006, Carter et al. 2010, Salonen \& Engström-Öst 2010). Close to our study area, Salonen et al. (2009) measured maximum turbidity levels of $14.6 \mathrm{NTU}$, and we observed turbidity levels of 5 to 18 NTU in the seining areas of the present study. This information was used to set the turbidity intervals used in the experiments.

\section{General experimental procedure}

We separated experimental fish from the holding tanks to a pre-experimental tank $36 \mathrm{~h}$ before a trial started. All selected fishes were starved $24 \mathrm{~h}$ before trials to equalise their hunger level. The experimental tank was filled to the desired level with turbid or clear water, and a transparent plastic tube $(8 \mathrm{~cm}$ diameter) was placed in the middle of the tank. A 
predetermined ratio of Daphnia (see 'Expt 1' and 'Expt 2', respectively) was added to the tank. We randomly selected 1 female stickleback from the preexperimental tank and transferred it to the transparent tube for $20 \mathrm{~min}$. The actual experiment started when the tube was gently pulled up and the fish was released. The fish was allowed to feed for $5 \mathrm{~min}$, which was the duration of each trial. Sticklebacks started feeding within a few seconds after being released. Fish that did not react within 1 min were discarded. After the foraging period, the fish was immediately removed, its total length was measured to the nearest $0.1 \mathrm{~cm}$ on a measuring board, and its wet mass weighed using an electronic balance $( \pm 0.01$ g). The water of the experimental tank was then filtered through a $0.5 \mathrm{~mm}$ sieve, and all remaining Daphnia in the sieve were counted. A fish was used only once, and all fishes were released at their respective collection site after the experiment.

\section{Expt 1}

In Expt 1, we offered hungry sticklebacks Daphnia of 2 different sizes (large and small) at 3 different ratios. The number of small Daphnia (50) was held constant across the treatments as we changed the number of large Daphnia (10, 20 or 50). This resulted in a change in both prey size ratios and prey density. Thus the ratios were 10:50, 20:50 and 50:50 large:small Daphnia, while the corresponding densities were 60, 70 and 100 Daphnia. These ratios were tested at 5 turbidity levels (clear, 5, 10, 15 and 20 NTU). The design corresponded to a factorial design with 3 prey size ratios by 5 turbidity treatments. All treatment combinations were repeated 15 times, resulting in a total sample size of 225 .

\section{Expt 2}

In Expt 2, prey density was kept constant at 80 Daphnia, while we manipulated the ratio of large to small Daphnia as 20:60, 40:40, and 60:20, respectively. Here, we used the 2 turbidity levels-clear and turbid ( $15 \pm 1 \mathrm{NTU}$ ) - that had provided clearly different foraging performances in the previous experiment. Hence, our experiment corresponded to a factorial design with a water quality treatment with 2 treatment levels, clear and turbid, and a prey ratio treatment consisting of the 3 prey ratios. Each combination was repeated 30 times, producing 180 trials.

\section{Statistical analyses}

Our main aim was to test if algal turbidity affects feeding success and prey selectivity, i.e. at what point suboptimal prey are excluded from the diet. To analyse feeding success, we used the total number of Daphnia eaten, and to measure diet choice, we used the proportion of small Daphnia eaten. Neither of these variables followed a normal distribution but were best modelled by a gamma error distribution. Therefore, we used generalised linear models with a gamma error distribution and log link function to analyse those data. Turbidity and prey size ratios were fixed factors, and fish size (total length, $\mathrm{mm}$ ) was used as a covariate. We first included all interaction terms in the models. In the case that interactions with the covariate were not significant (meaning that the slopes were homogenous), we excluded the interactions from the final model.

To highlight the active selection of prey (called 'prey selectivity'), we analysed the deviation from the expected proportion of small prey included in the diet as a ratio of the observed proportion of small prey to the expected proportion of small prey. In the replicates for Expt 2, there were 2 cases in which the sticklebacks consumed only large Daphnia. In these 2 cases, the deviation could not be calculated and was therefore replaced by the overall mean. All statistical analyses were done using SPSS 23.0.

\section{RESULTS}

\section{Expt 1}

Large sticklebacks Gasterosteus aculeatus consumed more Daphnia than the small ones across all turbidity levels (GLZ, gamma with log link, size effect, $p=0.002$; Table 1). Because the effect of body size on the number of prey eaten was similar for all treatments, we tested the main effects: turbidity and prey ratio. We found an overall negative effect of turbidity on food intake. With increasing turbidity, the total number of prey eaten decreased $(p<0.001$; Fig. 1), while there was no effect of prey ratio (Table 1) nor an effect of the interaction (Table 1).

In the analysis on the proportion of small prey included in the diet, there were no significant interactions between the covariate, fish size, and any of the main factors. Therefore, we excluded these interactions from the further analyses. Fish size did not affect the proportion of small prey included in the diet (Table 1). The proportion of small prey in the diet 
Table 1. Results of the statistical test of Expt 1. The results for 3 response variables are given. The interaction term refers to the interaction between the main factors prey ratio and turbidity. Response variables are indicated as headings

\begin{tabular}{|lrrr|}
\hline Explaining variable & Wald $\chi^{2}$ & df & \multicolumn{1}{c|}{$\mathrm{p}$} \\
\hline Total number of prey eaten & & & \\
Body size & 9.877 & 1 & 0.002 \\
Turbidity & 209.060 & 4 & $<0.001$ \\
Prey ratio & 0.942 & 2 & 0.624 \\
Interaction & 2.787 & 8 & 0.947 \\
Proportion of small prey included in the diet & \\
Body size & 2.316 & 1 & 0.128 \\
Prey ratio & 313.319 & 2 & $<0.001$ \\
Turbidity & 11.557 & 4 & 0.021 \\
Interaction & 7.038 & 8 & 0.533 \\
Prey selectivity & & & \\
Prey ratio & 1.035 & 2 & 0.596 \\
Turbidity & 10.936 & 4 & 0.027 \\
Interaction & 10.226 & 8 & 0.250 \\
\hline
\end{tabular}

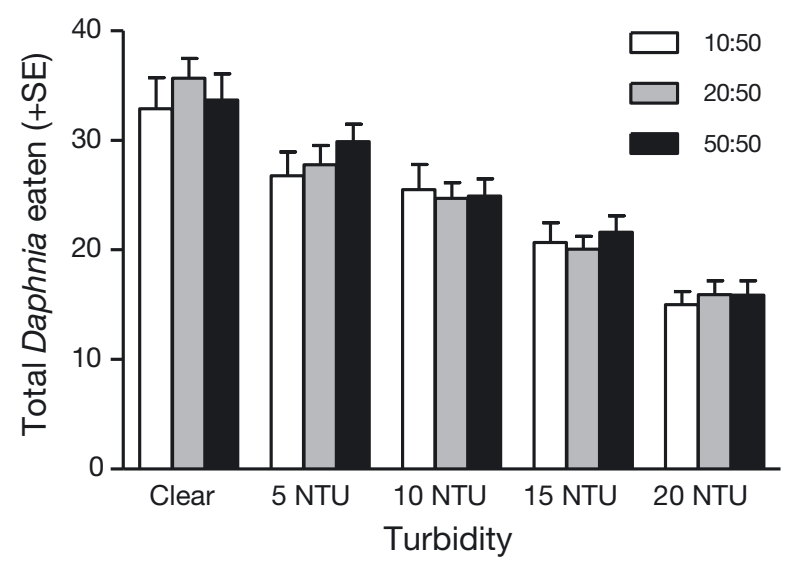

Fig. 1. Total number of Daphnia eaten at different turbidity levels and ratios of large to small prey $(10: 50,20: 50,50: 50)$ in Expt 1 done at Husö. NTU: nephelometric turbidity units

decreased with an increase in the ratio of large prey available ( $p<0.001)$. Increasing turbidity, however, increased the proportion of small Daphnia in the diet $(p=0.021)$. There was no interaction between prey ratio and turbidity (Table 1). The fish did not exclude the small prey type completely.

If the fish fed randomly, we would expect that the proportion of prey available is reflected in the diet. We therefore analysed prey selectivity as the deviation from the expected proportion of small prey included as a ratio of the observed to the expected. Doing so, the effect of prey ratio disappeared (Table 1), but the effect of turbidity remained $(\mathrm{p}=$ 0.027). All means were well below the random

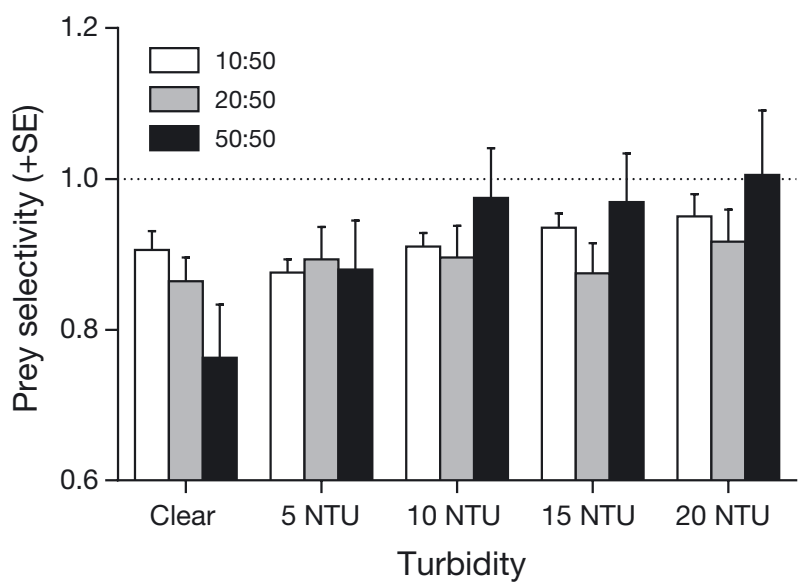

Fig. 2. Prey selectivity in the experiment done at Husö, where the prey availability was allowed to vary with the proportion of large and small prey (10:50, 20:50, 50:50). Selectivity is the deviation from the proportion of small Daphnia included in the diet if the fish had been feeding randomly. A selectivity of unity (dotted line) means that fish are including small and large prey in the proportion they are available. Most bars are below the line of unity, indicating that fish are discriminating against small prey. Only at the highest turbidities are small prey included at nearly random proportions. NTU: nephelometric turbidity units

expectation of unity, indicating a discrimination against small prey, except at the highest turbidities (Fig. 2), where prey were included according to availability. There was no interaction between prey ratio and turbidity (Table 1 ).

\section{Expt 2}

We found a general positive relationship between fish size and the number of Daphnia eaten $(\mathrm{p}=0.035$; Table 2), but there was no effect of turbidity (Table 2) or prey ratio (Table 2). There were no interactions between turbidity and ratio and fish size on the total number of prey eaten.

Fish size did not affect the proportion of small prey included in the diet (Table 2), nor were there any significant interactions between the covariate and the main factors, turbidity and prey ratio. However, the proportion of small prey consumed was affected both by turbidity ( $p=0.035$ ) and especially prey size ratio ( $p<0.001$; Table 2). Non-selective feeding would mean that large and small prey were included in the diet in the same proportion as they occurred in the habitat. Prey selectivity, however, varied and depended on both turbidity $(p=0.006)$ and prey size ratio ( $p=0.016$; Fig. 3 ). We observed that when the ratio of large to small prey was lowest $(20: 60)$, the 
Table 2. Results of the statistical tests of Expt 2, for 3 response variables. The interaction term refers to the interaction between the main factors prey ratio and turbidity. Response variables are indicated as headings

\begin{tabular}{|lrcc|}
\hline Explaining variable & Wald $\chi^{2}$ & $\mathrm{df}$ & $\mathrm{p}$ \\
\hline Total number of prey eaten & & & \\
Body size & 4.457 & 1 & 0.035 \\
Turbidity & 2.626 & 1 & 0.105 \\
Prey ratio & 0.226 & 2 & 0.896 \\
Interaction & 0.507 & 2 & 0.776 \\
Proportion of small prey included in the diet & \\
Body size & 0.853 & 1 & 0.356 \\
Turbidity & 4.464 & 1 & 0.035 \\
Prey ratio & 122.047 & 2 & $<0.001$ \\
Interaction & 2.875 & 2 & 0.237 \\
Prey selectivity & & & \\
Turbidity & 7.429 & 1 & 0.006 \\
Prey ratio & 8.306 & 2 & 0.016 \\
Interaction & 2.893 & 2 & 0.235 \\
\hline
\end{tabular}

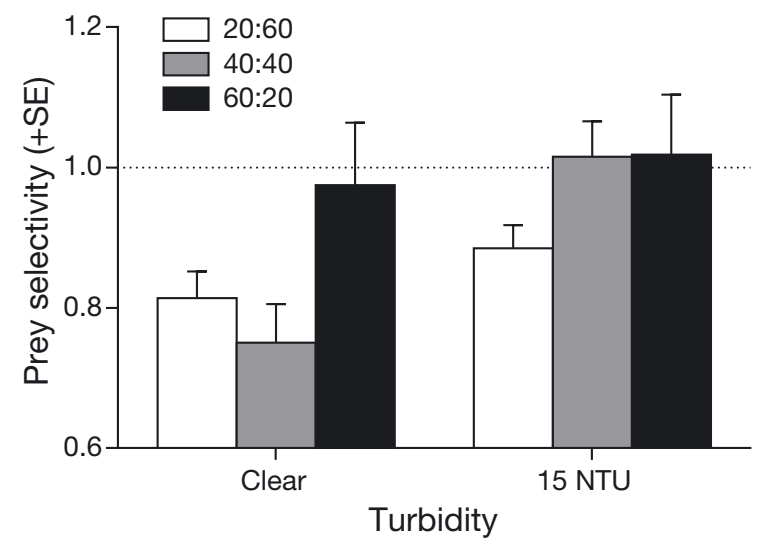

Fig. 3. Prey selectivity in the experiment done at Tvärminne, where prey availability was held constant while the proportion of large and small prey $(20: 60,40: 40,60: 20)$ was manipulated. Most bars are below unity, indicating that fish are discriminating against small prey. Only in turbid water at the highest large:small prey ratios are prey included at nearly random proportions. See Fig. 2 for more details

small prey were excluded disproportionately from the diet (Fig. 3). In turbid water, small prey were included at a higher rate and even at a 50:50 prey ratio, while in clear water, small prey were excluded until the ratio of large to small prey was 60:20 (Table 2).

\section{DISCUSSION}

Our results show that algal turbidity affects not only prey consumption but also prey selection of a planktivorous fish. When we experimentally con- trolled for the density of prey items, we found that turbidity affected prey choice, and sticklebacks Gasterosteus aculeatus showed a decreased discrimination against small prey under turbid conditions. This suggests that turbidity may cause suboptimal prey consumption in sticklebacks, at least from an energetic viewpoint. In Expt 1 where we exposed sticklebacks to a wide range of turbidities, higher turbidity levels had a clear negative impact on prey consumption. This suggests that turbidity negatively affects searching for or handling of prey items.

Previous studies show that predators become more selective towards energetically more beneficial prey when the encounter rate with these increases (Stephens \& Krebs 1986). In our experiments, we observed that prey selection in sticklebacks also alters with changes in the proportion of prey sizes and turbidity levels. Sticklebacks showed a discrimination against small prey and hence a preference for large prey at lower turbidity levels (clear and 5 NTU). At higher turbidity levels and when the proportion of large to small prey increased, they became increasingly random in their prey selection. In the experiment where we kept prey density constant, we found that when the ratio of large to small prey was lowest (20:60), the fish discriminated most against small prey. In turbid water, the fish switched to random feeding even at a 50:50 prey ratio, while in clear water, this did not happen until the ratio of large to small prey was 60:20. Again, this could have been due to the shorter reactive distances in turbid water, which in effect would mimic lower encounter rates and therefore favour random feeding (Werner \& Hall 1974). In a recent study, Kimbell \& Morrell (2016) found similar results to ours. They offered groups of 9-spined sticklebacks Pungitius pungitius a choice of small and large Daphnia and found that when large Daphnia were in a minority or equal in availability, the sticklebacks targeted large prey proportionately more. However, in turbid water, this preference disappeared, and fish fed randomly (Kimbell \& Morrell 2016).

According to the optimal diet theory, sticklebacks should have a threshold density of the most profitable prey at which they would stop consuming less profitable prey (Stephens \& Krebs 1986). In our study, we never observed such a threshold. The lack of threshold switching has also been observed in previous empirical studies (see e.g. Křivan 2010). However, the model assumes that prey arrive sequentially, whereas in our experiment, prey were simultaneously available. This means that the predators could target their attacks exclusively on the more 
profitable (large) prey that were within their field of view (Werner \& Hall 1974). Another reason for showing a preference for large prey could be that a larger apparent size stimulates a larger area of the retina (Lazzaro 1987), and fish are able to locate the prey from a greater distance. Reaction distance is known to increase with increasing prey size (Vinyard \& O'Brien 1976, Utne 1997), supporting the idea that large prey are detected earlier.

A hypothetical explanation for our findings is that increasing turbidity increasingly limits the sticklebacks' field of view. Within the field of view, the fish preferentially attacks large prey, and if the field of view is large enough, the fish can prey solely on large Daphnia. As the field of view decreases with increasing turbidity, the number of large prey visible is reduced, and the fish will increasingly include small prey in their diet, in such a way that their diet approaches the ratio of large to small prey available. In effect, this would mean that at higher turbidity levels, sticklebacks no longer feed selectively but include prey in their diet in a random manner, which is in line with our results from this study.

In nature, the limitation of the field of view caused by turbidity would lead to a situation where the effect of predators on the plankton community would be increasingly local. Aquatic planktivores are known to reduce or even eliminate large prey (Zaret 1980), and thus, they have a strong structuring effect on zooplankton communities. Anthropogenic eutrophication and hence turbidity is today a widespread problem in aquatic environments (Larsson et al. 1985, Cederwall \& Elmgren 1990, Selman et al. 2008). Our results suggest that turbidity, through its effect on predator diet choice, could potentially have drastic effects on the dynamics of zooplankton populations and the structure of zooplankton communities. Consequently, in turbid conditions, predation by planktivores would have a weaker effect on the size structure on zooplankton and instead mostly affect overall population density.

Food consumption decreased with increased turbidity. Prey detection depends on ambient light conditions, and turbidity decreases visibility by decreasing light penetration and reducing apparent contrast (Utne-Palm 2002). In our experiment, the foraging performance of the sticklebacks declined at higher turbidities, probably because the fish failed to detect the relatively transparent Daphnia due to poor visibility.

Many previous studies have shown that increasing turbidity reduces the reactive distance of fish, i.e. the distance at which they detect prey $\left(\mathrm{O}^{\prime} \mathrm{Brien}\right.$ et al.
1976, Gregory \& Northcote 1993, Sweka \& Hartman 2001, 2003). A decrease in reactive distance will result in a reduction in prey encounter rate (Sweka \& Hartman 2001), and as a result, foraging success is also reduced (Gardner 1981a, Zamor \& Grossman 2007, Carter et al. 2010, Wellington et al. 2010). An increase in the density of prey could potentially compensate for the decreased reaction distance (Sweka \& Hartman 2001). When we provided Daphnia at 3 different densities, we found no evidence for a compensating effect on total prey consumed. Instead, total prey consumption remained similar at all prey densities. We did not measure encounter rates directly, and it is possible that we did not increase prey density enough to offset the decrease in encounter rate caused by turbidity. However, the results may also suggest that the decreased prey consumption at higher turbidity levels may not merely be a function of encounter rate, but other mechanisms may also be involved. We note that in our experiment, the increase in prey density was achieved by adding large Daphnia only. Vinyard \& O'Brien (1976) showed that increased turbidity causes substantial reduction in the reactive distance particularly for large prey. This could be an additional reason why we did not observe a compensating effect of density on consumption.

It is possible that fish eventually lost their ability to attack or search for prey that were far away in conditions of higher turbidity. Our results would thus support the idea that 'turbidity act[s] like a cover' (Gregory 1993, p. 245) for Daphnia and help them to avoid potential predators. The fact that consumption was negatively related to turbidity level further strengthens this interpretation, as the increasing number of alternative prey not only diluted the relative predation pressure on individual prey but also the total predation pressure was decreased with increasing turbidity. From a prey population perspective, this decrease in predation pressure may have a destabilising effect on population dynamics (Begon et al. 2006), especially if at the same time the recruitment of additional predators is impeded (S. Sohel, S. Merilaita, K. Lindström pers. comm.).

The sticklebacks showed a general increase in prey consumption with body size. It is not surprising that larger individuals would generally require more food, and bigger sticklebacks have been shown to maintain higher feeding rates (Ranta \& Lindström 1990). However, in fish, visual acuity also correlates positively with body size (Walton et al. 1992, 1994). It is possible that large fish detected prey from a greater distance as they have larger eyes (Hairston et 
al. 1982) and better visual capacity than the smaller ones (Breck \& Gitter 1983). However, we did not observe an interaction between body size and turbidity, suggesting that large and small individuals were equally compromised by the turbidity.

In conclusion, the novel finding of our study is that algal turbidity reduced prey selectivity in fish, leading to random foraging. This could reduce the importance of fish predators as structurers of zooplankton populations.

Acknowledgements. We are grateful to staff at the Husö Biological Station and Tvärminne Zoological Station for excellent working facilities. Ella and Georg Ehrnrooth Foundation and Stiftelsens för Åbo Akademi forskningsinstitut (to SS) provided funding for this study. We also thank the anonymous reviewers who provided very helpful comments on earlier drafts of this manuscript.

\section{LITERATURE CITED}

Aksnes DL (2007) Evidence for visual constraints in large marine fish stocks. Limnol Oceanogr 52:198-203

Begon M, Harper JL, Townsend CR (2006) Ecology: individuals, populations and communities. Blackwell Publishing, Oxford

Bell AM, Foster SA (1994) Introduction to the evolutionary biology of the three spine stickleback. In: Bell AM, Foster SA (eds) The evolutionary biology of the threespine stickleback. Oxford University Press, Oxford, p 1-27

Blaber SJM, Blaber TG (1980) Factors affecting the distribution of juvenile estuarine and inshore fish. J Fish Biol 17: 143-162

Bonner TH, Wilde GR (2002) Effects of turbidity on prey consumption by stream fishes. Trans Am Fish Soc 131: 1203-1208

Breck JE, Gitter MJ (1983) Effect of fish size on the reactive distance of bluegill (Lepomis macrochirus) sunfish. Can J Fish Aquat Sci 40:162-167

Carter MW, Shoup DE, Dettmers JM, Wahl DH (2010) Effects of turbidity and cover on prey selectivity of adult smallmouth bass. Trans Am Fish Soc 139:353-361

Cederwall H, Elmgren R (1990) Biological effects of eutrophication in the Baltic Sea, particularly the coastal zone. Ambio 19:109-112

De Robertis A, Ryer CH, Veloza A, Brodeur RD (2003) Differential effects of turbidity on prey consumption of piscivorous and planktivorous fish. Can J Fish Aquat Sci 60: $1517-1526$

Dill LM (1983) Adaptive flexibility in the foraging behavior of fishes. Can J Fish Aquat Sci 40:398-408

Figueiredo BRS, Mormul RP, Benedito E (2015) Structural complexity and turbidity do not interact to influence predation rate and prey selectivity by a small visually feeding fish. Mar Freshw Res 66:170-176

* Gardner MB (1981a) Effects of turbidity on feeding rates and selectivity of bluegills. Trans Am Fish Soc 110:446-450

Gardner MB (1981b) Mechanisms of size selectivity by planktivorous fish: a test of hypotheses. Ecology 62: 571-578

Gill AB, Hart PJB (1994) Feeding behaviour and prey choice of the threespine stickleback: the interacting effects of prey size, fish size and stomach fullness. Anim Behav 47: 921-932

* Granqvist M, Mattila J (2004) The effects of turbidity and light intensity on the consumption of mysids by juvenile perch (Perca fluviatilis L.). Hydrobiologia 514:93-101

Gregory RS (1993) Effect of turbidity on the predator avoidance behaviour of juvenile chinook salmon (Oncorhynchus tshawytscha). Can J Fish Aquat Sci 50:241-246

*Gregory RS, Northcote TG (1993) Surface, planktonic, and benthic foraging by juvenile chinook salmon (Oncorhynchus tshawytscha) in turbid laboratory conditions. Can J Fish Aquat Sci 50:233-240

Guthrie DM, Muntz WRA (1993) Role of vision in fish behavior. In: Pitcher TE (ed) Behavior of teleost fishes. Chapman and Hall, London, p 75-113

*Hairston NG, Li KT, Easter SS (1982) Fish vision and the detection of planktonic prey. Science 218:1240-1242

Hart PJB, Gill AB (1994) Evolution of foraging behavior in the threespine stickleback. In: Bell AM, Foster SA (eds) The evolutionary biology of the threespine stickleback. Oxford University Press, Oxford, p 207-239

Helenius LK, Borg JP, Nurminen L, Leskinen E, Lehtonen H (2013) The effects of turbidity on prey consumption and selection of zooplanktivorous Gasterosteus aculeatus L. Aquat Ecol 47:349-356

Kärvenpää M, Lindström K (2004) Water turbidity by algal blooms causes mating system breakdown in a shallowwater fish, the sand goby Pomatoschistus minutus. Proc R Soc B 271:2361-2365

Johnsen S, Widder EA (1998) Transparency and visibility of gelatinous zooplankton from the Northwestern Atlantic and Gulf of Mexico. Biol Bull 195:337-348

Jönsson M, Ranåker L, Anders Nilsson P, Brönmark C (2012) Prey-type-dependent foraging of young-of-the-year fish in turbid and humic environments. Ecol Freshw Fish 21: 461-468

Jönsson M, Ranåker L, Nilsson PA, Brönmark C (2013) Foraging efficiency and prey selectivity in a visual predator: differential effects of turbid and humic water. Can J Fish Aquat Sci 70:1685-1690

Kimbell HS, Morrell LJ (2016) Turbidity weakens selection for assortment in body size in groups. Behav Ecol 27: $545-552$

K Křivan V (2010) Evolutionary stability of optimal foraging: partial preferences in the diet and patch models. J Theor Biol 267:486-494

Larsson U, Elmgren R, Wulff F (1985) Eutrophication and the Baltic Sea: causes and consequences. Ambio 14:9-14

Lazzaro X (1987) A review of planktivorous fishes: their evolution, feeding behaviours, selectivities, and impacts. Hydrobiologia 146:97-167

Milinski M (1982) Optimal foraging: the influence of intraspecific competition on diet selection. Behav Ecol Sociobiol 11:109-115

O'Brien WJ, Slade NA, Vinyard GL (1976) Apparent size as the determinant of prey selection by bluegill sunfish (Lepomis macrochirus). Ecology 57:1304-1310

Ohguchi O (1981) Prey density and selection against oddity by three-spined sticklebacks. Fortschritte der Verhaltensforschung, Heft 23 (Beiheft zur Zeitschrift für Tierpsychologie Bd. 57). Parey, Berlin

Quesenberry NJ, Allen PJ, Cech JJ (2007) The influence of turbidity on three-spined stickleback foraging. J Fish Biol 70:965-972 
Ranta E, Lindström K (1990) Assortative schooling in threespined sticklebacks? Ann Zool Fenn 27:67-75

Reguera P, Gomendio M (1999) Predation costs associated with parental care in the golden egg bug Phyllomorpha laciniata (Heteroptera: Coreidae). Behav Ecol 10: 541-544

Rowe DK, Dean TL (1998) Effects of turbidity on the feeding ability of the juvenile migrant stage of six New Zealand freshwater fish species. N Z J Mar Freshw Res 32:21-29

Rowe DK, Dean TL, Williams E, Smith JP (2003) Effects of turbidity on the ability of juvenile rainbow trout, Oncorhynchus mykiss, to feed on limnetic and benthic prey in laboratory tanks. N Z J Mar Freshw Res 37:45-52

Salonen M, Engström-Öst J (2010) Prey capture of pike Esox lucius larvae in turbid water. J Fish Biol 76:2591-2596

Salonen M, Urho L, Engström-Öst J (2009) Effects of turbidity and zooplankton availability on the condition and prey selection of pike larvae. Boreal Environ Res 14: 981-989

Sanden P, Håkansson B (1996) Long-term trends in Secchi depths in the Baltic Sea. Limnol Oceanogr 41:346-351

Selman M, Greenhaldh S, Diaz R (2008) Eutrophication and hypoxia in coastal areas: a global assessment of the state of knowledge. WRI Policy Notes. World Resources Institute, Washington, DC. www.wri.org/sites/default/files/ pdf/eutrophication_and_hypoxia_in_coastal_areas.pdf (accessed 12/10/2015)

Shaw GW, Pankhurst PM, Battaglene SC (2006) Effect of turbidity, prey density and culture history on prey consumption by greenback flounder Rhombosolea tapirina larvae. Aquaculture 253:447-460

Shoup DE, Drew Lane W (2015) Effects of turbidity on prey selection and foraging return of adult largemouth bass in reservoirs. N Am J Fish Manag 35:913-924

Shoup DE, Wahl DH (2009) The effects of turbidity on prey selection by piscivorous largemouth bass. Trans Am Fish Soc 138:1018-1027

Stephens DW, Krebs JR (1986) Foraging theory. Princeton University Press, Princeton, NJ

Stuart-Smith RD, Stuart-Smith JF, White RW, Barmuta LA (2007) The effects of turbidity and complex habitats on the feeding of a galaxiid fish are clear and simple. Mar Freshw Res 58:429-435

Sweka JA, Hartman KJ (2001) Influence of turbidity on brook trout reactive distance and foraging success. Trans Am Fish Soc 130:138-146

Sweka JA, Hartman KJ (2003) Reduction of reactive dis-

Editorial responsibility: Stylianos Somarakis,

Heraklion, Greece tance and foraging success in smallmouth bass, Micropterus dolomieu, exposed to elevated turbidity levels. Environ Biol Fishes 67:341-347

Utne ACW (1997) The effect of turbidity and illumination on the reaction distance and search time of the marine planktivore Gobiusculus flavescens. J Fish Biol 50: 926-938

Utne-Palm AC (1999) The effect of prey mobility, prey contrast, turbidity and spectral composition on the reaction distance of Gobiusculus flavescens to its planktonic prey. J Fish Biol 54:1244-1258

* Utne-Palm AC (2002) Visual feeding of fish in a turbid environment: physical and behavioural aspects. Mar Freshw Behav Physiol 35:111-128

V Valiela I, McClelland J, Hauxwell J, Behr PJ, Hersh D, Foreman K (1997) Macroalgal blooms in shallow estuaries: controls and ecophysiological and ecosystem consequences. Limnol Oceanogr 42:1105-1118

* Vinyard GL, O'Brien WJ (1976) Effects of light and turbidity on the reactive distance of bluegill (Lepomis macrochirus). J Fish Res Board Can 33:2845-2849

Vogel JL, Beauchamp DA (1999) Effects of light, prey size, and turbidity on reaction distances of lake trout (Salvelinus namaycush) to salmonid prey. Can J Fish Aquat Sci 56:1293-1297

*Walton WE, Hairston NG, Wetterer JK (1992) Growthrelated constraints on diet selection by sunfish. Ecology 73:429-437

Walton WE, Easter J, Malinoski C, Hairston J (1994) Sizerelated change in the visual resolution of sunfish (Lepomis spp.). Can J Fish Aquat Sci 51:2017-2026

Wellington CG, Mayer CM, Bossenbroek JM, Stroh NA (2010) Effects of turbidity and prey density on the foraging success of age 0 year yellow perch Perca flavescens. J Fish Biol 76:1729-1741

Werner EE, Hall DJ (1974) Optimal foraging and the size selection of prey by the bluegill sunfish (Lepomis macrochirus). Ecology 55:1042-1052

Wootton RJ (1976) The biology of the stickleback. Academic Press, London

Zamor RM, Grossman GD (2007) Turbidity affects foraging success of drift-feeding rosyside dace. Trans Am Fish Soc 136:167-176

Zaret T (1980) Predation and freshwater communities. Yale University Press, New Haven, CT

Zhang F, Hui C (2014) Recent experience-driven behaviour optimizes foraging. Anim Behav 88:13-19

Submitted: June 13, 2016; Accepted: December 13, 2016

Proofs received from author(s): February 15, 2017 